\title{
Antifungal Activity of Essential Oils from Some Medicinal Plants against Green Mold (Penicillium digitatum)
}

\author{
Zahra Ibrahim El-Gali \\ Dept. of Plant Protection, Faculty of Agriculture, Omer AlMuhktar University. El-Beida, Libya.
}

*Corresponding Author: Zahra Ibrahim El-Gali, Dept. of Plant Protection, Faculty of Agriculture, Omer AlMuhktar University. El-Beida, Libya.

\begin{abstract}
In this study; screened five essential oils for fungitoxic effect against Penicillium digitatum that infect orange fruits. The five essential oils were commercial products derived from clove, thyme, sesame, black cumin and cinnamon. Antifungal activity of essential oils was compared by poisoned agar technique. In laboratory; among essential oils clove was the most effective showed 100\% inhibition of mycelial growth at $1 \%$ concentration. Less antifungal effect was found with essential oils from cinnamon and thyme, while the oils from black cumin and sesame manifested no inhibition. Microscopic study on effect of essential oils on spores of $P$. digitatum showed distortion and shrinkage. Some essential oils might be promising source of a biological fungicide, applied directly before harvest or during postharvest.
\end{abstract}

Keywords: Essential oils, Antifungal, Penicillium digitatum, Biological control.

\section{INTRODUCTION}

Fruits and vegetables are often subject to varying levels of microbial decay during the growing season, harvesting, handling, transport and post-harvest storage and marketing conditions, or after purchasing by the consumer. Fruits contain high levels of sugars and nutrients, and their low $\mathrm{pH}$ makes them vulnerable to fungal decaying (Singh and Sharma 2007). Pathogenic fungi usually infect the host through wounds and cause significant economic losses in the commercialization stage (Gatto et al., 2011).

Green mold decay caused by the fungus Penicillium digitatum is a serious worldwide problem in citrus fruit and production (El-Gali, 2014; 2016 a). The use of manufactured chemicals as fungicides is a main method to prevent or delay diseases and the postharvest rot is well known. Outspread use of fungicides has significant disadvantage including increased cost, worry about fungicides residues on crop, as well as risk for human health and environment (Nikos and Costas, 2007). The developments of alternative non-synthetic chemical strategies, which better comply with organic food standards, are needed. Among the various strategies proposed, biological control using natural products such as plant extracts and essential oils show most promise.

Many plant essential oils and their volatile constituents have been reported to possess potent antifungal activities. Essential oils are represent a defence mechanism against pathogens and pests, produced in different plant section and they also have been shown to own antimicrobial and antifungicidal properties (Znini et al., 2011). Several studies have investigated the antifungal properties of essential oils against postharvest pathogens (Anjum and Akhtar, 2012 ; Jhaleger et al., 2015 ; Wang et al., 2017). For example, Vitoratos et al. (2013) recorded inhibition in mycelial growth of Botrytis cinerea, $P$. digitatum and P. italicum under effect of plant essential oils in culture plates. The rosemary leaves oil has reported to be effective against $P$. digitatum in vitro (Handel et al., 2016). In the other study, Louhibi et al. (2016) recently reported the effective inhibition of the green mold fungus using essential oils derived from Lavandula hybrida and Artemisia herba alba. In this study, the essential oils derived from four medicinal plants (clove, cinnamon, thyme, sesame and black 
cumin) were evaluated for efficacy against Penicillium digitatum under a modified atmosphere environment in vitro.

\section{MATERIALS AND METHODS}

\section{Pathogen}

Isolate of $P$. digitatum, was originated naturally infected sour orange fruits and maintained on potato sucrose agar(PSA) at $4{ }^{\circ} \mathrm{C}$. Fresh cultures of the fungus were prepared by subculture of mycelia onto new PSA plate and the incubated at $23{ }^{\circ} \mathrm{C}$ for 3-5 days.

\section{Oils}

Commercial essential oils of plants were including clove (Syzygium aromaticum), cinnamon (Cinnamomum aromaticum), sesame (Sesamum indicum), black cumin (Nigella sativa) and thyme (Thymus vulgaris) and were obtained from Alexandria Company for Medicinal Industries.

\section{Growth study}

In the growth study, different essential oils were incorporated with potato agar medium in $1 \%$ concentration The $P$. digitatum was allowed to grow in the above test and control media. The diameter of the colony in both were measured and the percent inhibition to growth was deduced using the following formula.

$$
\text { Percent inhibition }=\frac{\mathrm{a}-\mathrm{b}}{\mathrm{a}} \times 100
$$

where ' $a$ ' is the radial growth of the colony in the control medium and 'b' the radial growth in the test medium.

\section{Microscopic study of effect of EO on fungal mycelium and spores}

Fifty microliters of EO were put on the center of the glass slides. Fresh fungal mycelium piece bearing spores was taken out of petriplate with inoculating needle and immersed in the drop of clove oil on slides. After $1 \mathrm{~h}$ of incubation at ambient temperature, the slides were examined under light microscope and photographed.

\section{Statistical analysis}

Data were converted by using the formula Arc sin_x (Yazdi Samadi et al, 1997). Statistical analysis was performed with COSTAT and chart was drawn by Excel 2010 software.

\section{RESULTS AND DISCUSSION}

The effect of some essential oils on mycelial growth of $P$. digitatum was presented in Fig. 1. The results indicated that, the essential oils gave different effectives against fungal growth. Inhibition zone diameters of $P$. digitatum was completely inhibited by exposure to clove oil at $1 \%$, while the oils from black cumin and sesame manifested no inhibition. The effect of several plant species essential oils was investigated by Abd-alla et al. (2014) ; El-Gali (2016 b) and Pandey et al. (2017). The pathway of activity of these complexes against fungi is unidentified but may be interrelated to their general capability to soften or otherwise dislocate the reliability of cell membranes and cell walls (Isman and Machial, 2006).

Clove oil could completely stop fungal growth. The results of thyme oil was followed by cinnamon oil, whose lowest showed $28.2 \%$ and $24.6 \%$ mycelial growth inhibition respectively. No effect was recorded at used black cumin oil, it was enhancing mycelia growth. Several studies reported that clove oil was most effective against radial fungal growth (Anjum and Akhtar, 2012 ; Hamini-Kadar, 2014 ; El-Gali. 2016). Cox et al. (2000) reported that tea tree oil inhibited respiration and increased the permeability of cell cytoplasmic and plasma membranes. 


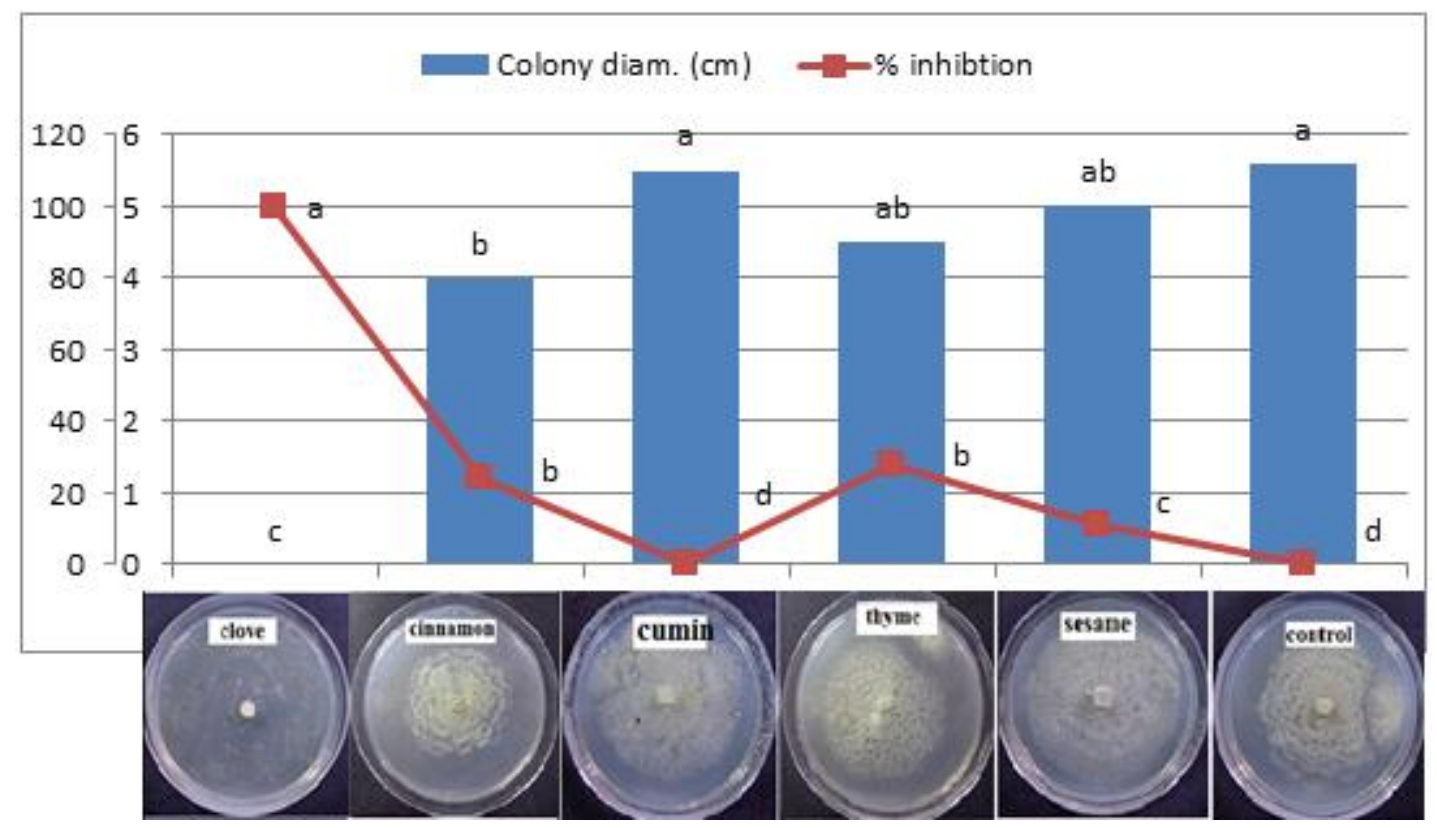

Figure 1. Antifungal activity of 5 essential oils against mycelial growth of P. digitatum on PSA medium. (Columns followed by the same letter( $s$ ) are not significantly different at $P=0.05$ )

In addition to all oils were changed in spores morphology. After $1 \mathrm{hr}$ of treatment of fungal bearing spores with essential oils, lysis and distortion of spores was observed in the fungal spores (Fig. 2). The effect was profound and clearly visible in form of deformities and retraction of spore structure, such as thickness in cell wall and renal or lunar shape were observed. Microscopic study on effect of clove oil on spores of Mucor sp. and M. gypseum showed distortion and shrinkage (Rana, et al., 2011). Park et al. (2007) studied effect of clove oil on Trichophyton mentagrophytes with the help of transmission electron microscope. They observed the expansion of its endoplasmic reticulum near the cell membranes of a hyphal specimen treated with eugenol. In addition, the inner mitochondrial membranes were partially destroyed, with complete destruction of the cell wall. The accumulation of hydrocarbon molecules resulted in swelling of the membrane bilayer, as assessed by the release of fluorescence self-quenching of fluorescent fatty acid and phospholipid analogs. These effects on the integrity of the membrane caused an increased passive flux of protons and carboxyfluorescein. The effective concentrations of the different cyclic hydrocarbons correlated with their partition coefficients between the membrane and aqueous phase. The impairment of microbial activity by the cyclic hydrocarbons most likely results from hydrophobic interaction with the membrane, which affects the functioning of the membrane and membrane-embedded proteins (Sikkema, et al., 1994).

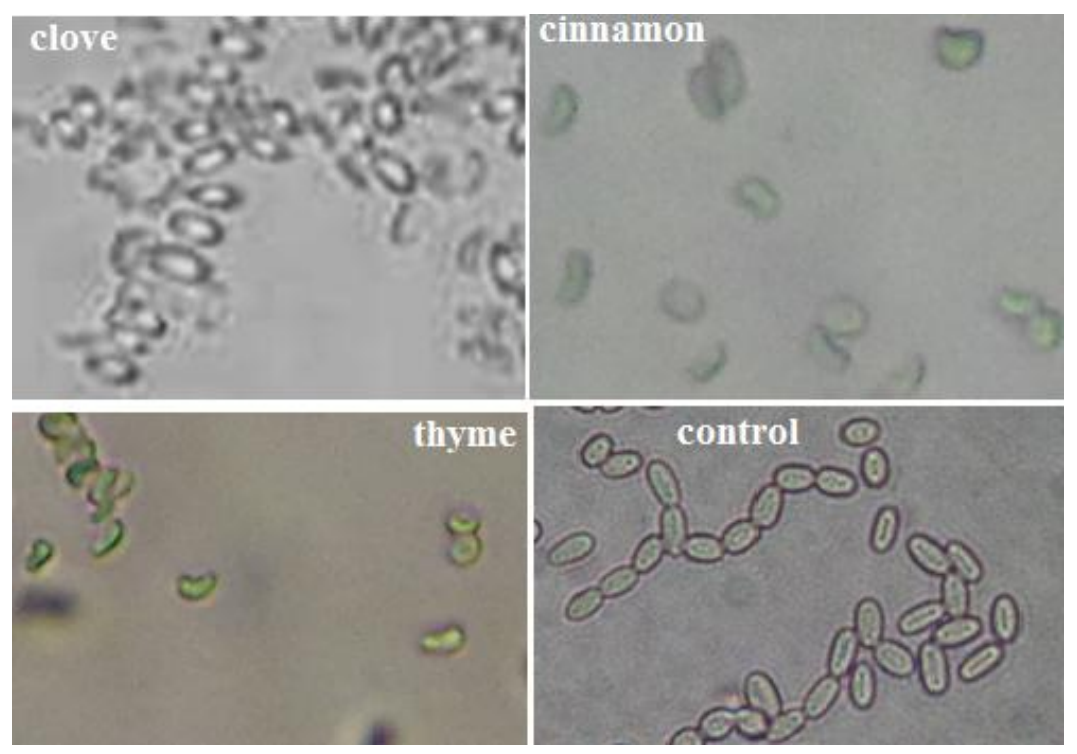

Figure 2. Abnormal spores of $P$. digitatum treated with essential oil compared with the untreated (Con.). 


\section{CONCLUSION}

In conclusion this preliminary study showed that the essential oils derived from clove, cinnamon and thyme maybe used as alternative for the control of green mold on postharvest organic fruits especially as a natural fumigant in closed container or packaging.

\section{REFERENCES}

[1] Abd-Alla, M.A., El-Gamal, N.G., El-Mougy, N.S. and Abdel-Kader, M.M., (2014). Post-harvest treatments for controlling crown rot disease of Williams banana fruits (Musa acuminata L.) in Egypt. Plant Pathology and Quarantine, 4(1): 1-12.

[2] Anjum, T. and Akhtar, N. (2012). Antifungal activity of essential oils extracted from clove, cumin and cinnamon against blue mold disease on citrus fruit. International Conference on Applied Life Sciences (ICALS) Turkey, September 10-12, 321-326.

[3] Cox, S.D., Mann, C.M.I., Markham, J.L., Bell, H.C., Gustafson, J.E. and Warmington, J.R. (2000).The mode of antimicrobial action of the essential oil of Melaleuca alternifolia (tea tree oil). J. Appl. Microbiol., 88: $170-175$.

[4] El-Gali, Z.I. (2014). Control of Penicillium digitatum on orange fruits with calcium chloride dipping. Journal of Microbiology Research and Reviews, 2(6): 54-61.

[5] El-Gali, Z.I. (2016 a). Isolation and identification of fungi associated with fruits sold in local markets. IJRSB., 4(11): 61- 64 .

[6] El-Gali, Z.I. (2016 b). Antifungal activity of some essential oils on fungal growth and aflatoxin production. International Journal of Phytopharmacy Research. 7(1): 13-17.

[7] Gatto MA, Ippolito A, Linsalata V, Cascarano NA, Nigro F, Vanadia S, Di Venere D (2011). Activity of extracts from wild edible herbs against postharvest fungal diseases of fruit and vegetables. Postharvest Biology and Technology 61:72-82.

[8] Hendel, N., Larous, L. and Belbey, L. (2016). Antioxidant activity of rosemary (Rosmarinus officinalis L.) and it's in vitro inhibitory effect on Penicillium digitatum. Inter. Food Res. J. 23(,4): 1725-1732.

[9] Isman, M.B. and Machial, C.M. (2006). Pesticides based on plant essential oils: from traditional practice to commercialization. In M. Rai and M.C. Carpinella (eds.), Naturally Occurring Bioactive Compounds, Elsevier, BV, pp 29-44.

[10] Jhalegar, J., Sharma R.R. and Singh, D. (2015). In vitro and in vivo activity of essential oils against major postharvest pathogens of Kinnow (Citrus nobilis $\times$ C. deliciosa) mandarin MD. J. Food Sci. Technol., 52(4):2229-2237.

[11] Louhibi, S., Elghadraoui, L. and Amiri, S. (2016). Inhibitory effect of some spice essential oils on Penicillium digitatum causing postharvest green rot in citrus. Inter. J. of Sci. and Res., 5(11):1122-1124

[12] Nikos, GT. and Costas, DE. (2007). Antifungal activity of lemongrass (Cympopogon citrates L.) essential oil against key postharvest pathogens. Innovative Food Science and Emerging Technologies 8:253-258.

[13] Pandey, A.K., Kumar, P., Singh, P., Tripathi, N.N. and Bajpai, V.K. (2017). Essential Oils: Sources of Antimicrobials and Food Preservatives. Frontiers in Microbiology, 7: 1- 14.

[14] Park, M.J., Gwak, K.S., Yang, I., Choi, W.S., Jo, H.J., Chang, J.W., Jeung, E.B. and Choi, I.G. (2007). Antifungal activities of the essential oils in Syzygium aromaticum (L.) Merr. Et Perry and Leptospermum petersonii Bailey and their constituents against various dermatophytes. The J. Microbiol., 45: 460-465.

[15] Rana, I.S., Rana, A.S. and Rajak, R.C. (2011). Evaluation of antifungal activity in essential oil of Syzygium aromaticum by extraction, purification and analysis of its main component eugenol. Brazilian J. of Microbiol., 42: 1269-1277

[16] Singh, D. and Sharma, RR. (2007). Postharvest diseases of fruit and vegetables and their management. In: Prasad, D. (Ed.), Sustainable Pest Management. Daya Publishing House, New Delhi, India

[17] Sikkema, J., de Bont, J.A.M. and Poolman, B. (1994). Interactions of cyclic hydrocarbons with biological membranes. J. Biol. Chem., 269: 8022- 8028.

[18] Vitoratos, A., Bilalis, D., Karkanis, A. and Efthimiadou, A. (2013). Antifungal Activity of Plant Essential Oils Against Botrytis cinerea, Penicillium italicum and Penicillium digitatum. Not Bot Horti Agrobo, 41(1):86-92

[19] Wang, Y., Bian, W., Ren, X., Song, X. and He, S. (2017). Microencapsulation of clove essential oil improves its antifungal activity against Penicillium digitatum in vitro and green mould on Navel oranges. The J. of Hort. Sci. and Biotech., 1-8 p.

[20] YazdiI Samadi, B., Rezaei, A. and Valyzadeh, M. (1997). Statistical Design in Agricultural Research. Teh. Uni. Pub. 234 pp. 
Antifungal Activity of Essential Oils from Some Medicinal Plants against Green Mold (Penicillium digitatum)

[21] Znini, M., Cristofari, G., Majidi, L., Mazouz, H., Tomi, P., Paolini, J. and Costa, J. (2011). Antifungal activity of essential oil from Asteriscus graveolens against postharvest phytopatogenic fungi in apples. Natural Product Communicatio

Citation: Z. I. El-Gali, "Antifungal Activity of Essential Oils from Some Medicinal Plants against Green Mold (Penicillium digitatum) ", International Journal of Advanced Research in Botany, vol. 4, no. 2, p. 1-5, 2018. http://dx.doi.org/10.20431/2455-4316.0402001

Copyright: $\odot 2018$ Z. I. El-Gali. This is an open-access article distributed under the terms of the Creative Commons Attribution License, which permits unrestricted use, distribution, and reproduction in any medium, provided the original author and source are credited. 